\title{
Weight loss as a prognostic factor for recurrence and survival in oropharyngeal squamous cell carcinoma patients
}

\author{
ANTUANI RAFAEL BAPTISTELLA ${ }^{1-3}$, KLISMAN DRESCHER HILLESHEIN ${ }^{3}$, \\ CAROLINE BEAL ${ }^{3}$, JULIANA S. BRAMBATTI ${ }^{3}$, RUGGERO CARON ${ }^{1,3,4}$, SHALINE FERLA BAPTISTELLA ${ }^{1-4}$, \\ RADAMÉS ÁDAMO ZUQUELLO ${ }^{5}$, CARINA ROSSONI ${ }^{1-3}$ and GABRIEL MANFRO ${ }^{1,3,6}$ \\ ${ }^{1}$ Oncology Research Group, Santa Terezinha University Hospital, Joaçaba; ${ }^{2}$ Postgraduate Program in Bioscience and Health, \\ University of West Santa Catarina; ${ }^{3}$ Faculty of Medicine, University of West Santa Catarina; ${ }^{4}$ Department of Clinical Oncology, \\ Santa Terezinha University Hospital, Joaçaba, SC 89600-000, Brazil; ${ }^{5}$ Department of Medicine, Miller School of Medicine, \\ University of Miami, Miami, FL 33136, USA; ${ }^{6}$ Department of Oncological Surgery, \\ Santa Terezinha University Hospital, Joaçaba, SC 89600-000, Brazil
}

Received May 21, 2018; Accepted September 4, 2018

DOI: $10.3892 / \mathrm{mco} .2018 .1737$

\begin{abstract}
Although the mortality rate of oropharyngeal squamous cell carcinoma (OPSCC) has been decreasing over the last 30 years, there has been a significant increase in the frequency of diagnosis of this type of cancer in several countries. Beyond the classic prognostic factors, such as TNM stage, there is a lack of predictive factors for recurrence and treatment response. A retrospective analysis of patients with OPSCC treated at the Oncology Department of the Santa Terezinha University Hospital between 2007 and 2012 was performed, with the aim of identifying new prognostic factors. In addition to the significance of clinical stage as a prognostic factor for recurrence, OPSCC patients with advanced TNM stage and those treated with radiotherapy, chemoradiation or palliative measures, had a worse prognosis. Patients with moderate or severe weight loss $(>5 \%)$ at diagnosis had a higher tumor recurrence rate compared with those with mild or no weight loss $(\mathrm{P}=0.007)$. Furthermore, $76.9 \%$ of patients with moderate or severe weight loss, as opposed to $13.3 \%$ of patients with mild or no weight loss, eventually succumbed to the disease $(\mathrm{P}=0.0001)$. These data suggest that moderate and severe weight loss at diagnosis is a prognostic factor for OPSCC and it is associated with disease recurrence.
\end{abstract}

Correspondence to: Professor Antuani Rafael Baptistella, Postgraduate Program in Bioscience and Health, University of West Santa Catarina, 2125 Rua Getulio Vargas, Joaçaba, SC 89600-000, Brazil

E-mail: antuani.baptistella@unoesc.edu.br

Key words: weight loss, prognostic factor, oropharyngeal squamous cell carcinoma, recurrence

\section{Introduction}

Head and neck tumors are a major public health concern, particularly in developing countries, as they are associated with high morbidity and mortality rates $(1,2)$. This type of cancer has an incidence of 2-3\%, making it the sixth most common type of cancer worldwide (3). Based on data collected between 2007 and 2011, the newly diagnosed cases of oropharyngeal cancer were 10.9 per 100,000 inhabitants per year, with 2.5 deaths per 100,000 individuals. The 5-year overall survival for this type of cancer was reported to be $62.7 \%$ (4).

The extent of the disease in terms of local invasion, lymph node involvement and distant organ metastases at the time of diagnosis is an important prognostic factor, with a 5-year survival rate of $75 \%$ for localized (stage I) oropharyngeal carcinomas and $<25 \%$ for metastatic (stage IV) disease (5).

Over $90 \%$ of upper airway/digestive tract cancers are of the squamous cell carcinoma (SCC) type. This disease is multifactorial, as its development results from the interaction of environmental and genetic factors (6). The great majority of lesions in the pharynx occurs in the oropharynx (40-50\%); the tonsillar region is affected in $40 \%$ and the base of the tongue in $30 \%$ of the cases (7). Oropharyngeal cancers include malignant neoplasms occurring in the tonsillar region, base of the tongue, soft palate and posterior pharyngeal wall (8).

The most important etiological factor for the development of head and neck cancer is tobacco use, with the relative risk increasing 10 -fold in smokers (9). Smoking together with alcohol consumption produce a synergistic tumorigenic effect (10) that increases the risk of head and neck SCC 40 -fold (2). This association is responsible for $>80 \%$ of the cases of oropharyngeal cancer diagnosed worldwide (11), whereas smoking and alcohol cessation acts protectively against the development of head and neck SCC (12). Furthermore, over the last decades, a strong causal association between human papillomavirus (HPV) infection and the development of SCC has been established $(7,13)$, characterizing HPV infection as 
another important risk factor for oropharyngeal SCC (OPSCC) development $(14,15)$.

In addition to these major factors, diet also affects the risk of cancer development. Certain vitamins or pigments, such as carotenoid, may be protective when included in a balanced diet. However, vitaminosis, particularly from vitamin A, beta-carotene and selenium, and folate deficiency, may represent nutritional risks for cancer development $(16,17)$. Another nutritional factor associated with the development of OPSCC is the consumption of mate and chimarrão (Ilex paraguariensis) (18-20), which is quite popular in Latin American countries.

Early diagnosis of OPSCC is a major factor affecting survival. The survival rate may reach $94 \%$ when the lesions are small and localized; however, it decreases to $25 \%$ in metastatic disease (21). Weight loss has been reported as a sign of cancer, as $25 \%$ of patients with an involuntary weight loss of $>5 \%$ body weight in 6 months are diagnosed with cancer (22). In head and neck cancer, critical weight loss $(>5 \%$ in 1 month or $>10 \%$ in 6 months) has been reported in $20-57 \%$ of the patients at diagnosis, usually caused by dysphagia and/or loss of taste or appetite (23).

Given the incidence, mortality and consequent impact on health caused by head and neck tumors, it is crucial to identify factors that may be of predictive and prognostic value. The objective of the present study was to identify factors associated with prognosis and recurrence in patients diagnosed with OPSCC.

\section{Materials and methods}

Study cohort. The medical records of patients diagnosed with OPSCC and treated at the Oncology Department of the Santa Terezinha University Hospital (Joaçaba, Brazil) between 2007 and 2012 were retrospectively analyzed after obtaining approval from the hospital's Research Ethics Committee.

The inclusion criteria were histologically confirmed OPSCC and completion of the treatment schedule. Patients for whom medical records or weight measurements were unavailable were excluded from the study. The study cohort was composed of 45 patients. However, for the mortality analysis, 4 patients were excluded due to withdrawal of treatment or death by another cause. Furthermore, for the recurrence analysis, 16 patients were excluded due to disease progression, finally leaving a total of 29 patients.

All 45 patients were treated and staged by the same professional (G.M.). Medical records were reviewed to extract data on patient and tumor characteristics. The patients were classified by sex, age, tumor subsite localization (soft palate, tongue base or tonsils), tumor stage (based on the TNM staging classification) (24), time with symptoms ( $>5$ or $<5$ months), type of treatment, risk factors (smoking, smoking and consumption of alcoholic beverages and no smoking) and weight loss at diagnosis (moderate and severe, when the patients exhibited a decrease of $5 \mathrm{~kg}$ or $>5 \%$ of their initial body weight over a period of 6 months, and mild when the weight loss was $<5 \mathrm{~kg}$ or $<5 \%$ body weight) (25).

Statistical analysis. Statistical analyses were performed using IBM SPSS Statistics 22 (IBM Corp., Armonk,
NY, USA). To compare the groups, Fisher's exact test and Pearson's Chi-squared univariate analysis were used. A P-value of $<0.05$ was considered to indicate statistically significant differences.

\section{Results}

Patient characteristics. To identify factors potentially associated with recurrence in OPSCC, 45 patients diagnosed between 2007 and 2012 were retrospectively investigated. The mean age of this cohort at diagnosis was 57.6 years, and $86.7 \%$ of the patients were male. In this patient cohort, $93.3 \%$ (41) of the patients were smokers, and $71.1 \%$ (32) also reported heavy alcohol consumption. Only $6.7 \%$ (3) of the patients were non-smokers or ethanol abusers. The most common tumor subsite localization was the base of the tongue, affecting $51.1 \%$ (23) of the patients, followed by the tonsils in $31.1 \%$ (14) and the soft palate in $17.8 \%$ (8) of the cases (Table I).

From the initial cohort, 4 patients abandoned treatment and the 5-year overall survival rate among the remaining 41 patients was $46.3 \%$. A total of 12 patients did not respond to treatment and were therefore not evaluated for recurrence.

Follow-up. After treatment, 29 patients were followed up and 7 (24\%) developed recurrence. When comparing the patients without recurrence to those with recurrence, there were no differences regarding tumor subsite localization, tumor size (T), lymph node involvement or type of treatment. In the group of patients who were symptomatic for $<5$ months $15.8 \%$ had recurrence, whereas $40 \%$ of patients who were symptomatic for $>5$ months had recurrence. Among patients who did not have metastases at diagnosis, 20\% developed recurrence, compared with $50 \%$ amongst those with metastases at diagnosis. However, these results were not statistically significantly different. Tumor stage differed significantly $(\mathrm{P}=0.022)$ between the groups with and without recurrence. Among patients with stage I and III disease, 16.7 and $11.1 \%$, respectively, developed recurrence, while $35.7 \%$ of stage IV patients developed recurrence.

Role of weight loss in recurrence. Another factor associated with recurrence was weight loss. In this cohort, $100 \%$ of patients without weight loss or with only mild weight loss at diagnosis did not have recurrence. However, $43.8 \%$ of patients with moderate or severe weight loss developed recurrence $(\mathrm{P}=0.007$; Table II).

Survival analysis. At 5 years, 19 of the 41 patients (46.3\%) remained alive, while $22(53.7 \%)$ had succumbed to the disease. When comparing the surviving and deceased patient groups, tumor subsite localization did not differ significantly between the two $(\mathrm{P}=0.47)$. Although $83.3 \%$ of patients with tumors in the soft palate survived, only 45.5 and $30.8 \%$ of patients with tumors in the base of the tongue and tonsils, respectively, survived.

In the present study, the statistical analysis demonstrated that TNM stage was an important prognostic factor for survival, both when analyzed separately as well as in the clinical stages. In patients with T1, T2 and T3 tumors, the survival rate was 66.7, 75 and $64.3 \%$, respectively. However, only $23.1 \%$ of patients with $\mathrm{T} 4 \mathrm{a}$ and none of the patients with $\mathrm{T} 4 \mathrm{~b}$ survived $(\mathrm{P}=0.003)$. In the group of patients without lymph node invasion (N0), 70.6\% 
Table I.Baseline characteristics of patients with nasopharyngeal squamous cell carcinoma.

\begin{tabular}{lc}
\hline Characteristics & $\mathrm{n}(\%)$ \\
\hline Mean age, years & 57.6 \\
Sex & \\
Male & $39(86.7)$ \\
Female & $6(13.3)$ \\
Tumor subsite localization & \\
Tongue base & $23(51.1)$ \\
Tonsils & $14(31.1)$ \\
Soft palate & $8(17.8)$ \\
Risk factors & \\
Smoking & $10(22.2)$ \\
Smoking + alcohol consumption & $32(71.1)$ \\
No smoking & $3(6.7)$ \\
\hline
\end{tabular}

survived, whereas among patients with lymph node invasion (N1), only $29.2 \%$ survived $(\mathrm{P}=0.01)$. Patients without distant metastasis at diagnosis (M0) had a survival rate of $54.5 \%$, while those with metastasis (M1) had a $12.5 \%$ survival rate at 5 years $(\mathrm{P}=0.037)$. The survival rate for patients with stage I, II and III disease was 80,100 and $80 \%$, respectively, while only $24 \%$ of patients diagnosed at stage IV survived $(\mathrm{P}=0.0006)$.

The type of treatment was also associated with differences in survival. Patients treated with surgery alone had a survival rate of $75 \%$, whereas patients treated with radiotherapy or radiochemotherapy had survival rates of 33.3 and $37.5 \%$, respectively. None of the patients who received palliative therapy survived $(\mathrm{P}=0.018)$.

Finally, weight loss proved to be a powerful prognostic factor for survival in OPSCC. In the group with no weight loss or only mild weight loss, $86.7 \%$ of patients survived. However, among patients with moderate or severe weight loss at diagnosis, the survival rate was only $23.1 \%$ ( $\mathrm{P}=0.0001)$ (Table III).

\section{Discussion}

In the present study, the mean age of patients with OPSCC was 57.6 years, and the majority were men and smokers. Previous studies reported a similar profile for OPSCC patients, with a mean age of 59 years (26) and an $80.3 \%$ male predominance (27). In a study published by Perry et al (2015), $79.3 \%$ of the patients with OPSCC were men, and $85.6 \%$ were smokers in the entire cohort (28). Although tobacco and alcohol consumption are well-documented risk factors for head and neck cancer, their role in oropharyngeal cancer is less clear (9). In this cohort of patients, the most common subsite was the base of the tongue (51.1\%), which was different from a study on 37,452 OPSCC patients reporting that the most commonly affected subsite was the tonsils (1). In the present study, the 5-year overall survival rate was $46.3 \%$, which was similar to the SEER 2016 data (4), reporting a survival rate of $43 \%$ specifically for this type of tumor. The poor prognosis of oropharyngeal cancer when compared with oral cavity cancer may be associated with the fact that oropharyngeal cancer is not frequently diagnosed at an early stage. Only $14 \%$ of patients were diagnosed with early-stage disease, whereas the majority $(55 \%)$ were diagnosed with regional metastasis (4). The recurrence rate in the present study was $24 \%$, which was higher compared with that reported previously by Garden et al (2013) and Roskies et al (2016), who demonstrated a recurrence rate of 18 and $11 \%$, respectively $(29,30)$. The increased recurrence rate reported herein may be due to late diagnosis, as $79.3 \%$ of patients were diagnosed with stage III and IV disease.

Of the patients evaluated, $45.5 \%$ were diagnosed with advanced local disease (T4) and 58.5\% with lymph node involvement, showing a predominance of more advanced stage at diagnosis, consistently with previous findings $(1,3)$. Tumor size (T), lymph node involvement $(\mathrm{N})$ and distant metastasis (M) were not associated with recurrence, but they were important prognostic factors for survival in OPSCC. Over the last four decades, it has been demonstrated that extranodal spread is the single most important prognostic factor for SCC of the head and neck (31). In addition, another study reported that tumor size, lymph node involvement and distant metastasis are not only important prognostic factors for survival, but also for recurrence in OPSCC patients (32). The late diagnosis in these patients is also reflected by clinical stage, as $61 \%$ were diagnosed at stage IV, which is common for this type of cancer (14). Clinical stage was an important factor associated with recurrence and prognosis in these patients. The mortality rate for stage IV disease reached $76 \%$, while it was 20,0 and $20 \%$ for stages I, II and III, respectively. Further research demonstrated that TNM stage has a good prognostic power, mainly in non-HPV oropharyngeal cancer cases (33).

Although the majority of the patients were diagnosed with advanced-stage disease, $65.5 \%$ had been symptomatic for $<5$ months prior to diagnosis, which further supports the hypothesis that early-stage OPSCC does not commonly present with alarming symptoms $(3,34)$. In a Brazilian study, the mean evolution time (the time between the initiation of symptoms to diagnosis) for patients with OPSCC was 6.4 months (35). Furthermore, it has been reported that the time from symptom onset to treatment initiation is correlated not only with more advanced disease stage at diagnosis, but also with OPSCC patient survival (3). However, in the present study, the time from symptom onset to treatment initiation was not correlated with recurrence.

Chemoradiation therapy is used for patients who are not surgical candidates due to extensive tumor burden (26). The majority of the patients in this study $(58.5 \%)$ were treated with chemoradiation due to the late stage at diagnosis. It was observed that the type of treatment, which depends on tumor stage, was correlated with survival. Patients treated with surgery had a survival rate of $75 \%$, while patients treated with radiotherapy and chemoradiation had a survival rate of 33.3 and $37.5 \%$, respectively. None of the patients who received palliative treatment survived.

In the present study, moderate or severe weight loss proved to be an important prognostic factor in OPSCC. A total of 76.9\% of patients with moderate or severe weight loss succumbed to the disease, while $86.7 \%$ of patients with mild or no weight loss survived $(\mathrm{P}=0.0001)$. Furthermore, we observed an important 
Table II. Clinical characteristics of patients with nasopharyngeal squamous cell carcinoma, with and without tumor recurrence.

\begin{tabular}{|c|c|c|c|}
\hline Characteristics & Without tumor recurrence $n=22(\%)$ & With tumor recurrence $\mathrm{n}=7(\%)$ & P-value \\
\hline Tumor subsite & & & 0.5 \\
\hline Tongue base & $10(71.4)$ & $4(28.6)$ & \\
\hline Tonsil & $6(75.0)$ & $2(25.0)$ & \\
\hline Soft palate & $6(85.7)$ & $1(14.3)$ & \\
\hline Time of symptoms & & & 0.16 \\
\hline$>5$ months & $6(60.0)$ & $4(40.0)$ & \\
\hline$<5$ months & $16(84.2)$ & $3(15.8)$ & \\
\hline Weight loss & & & 0.007 \\
\hline None/mild & $13(100.0)$ & $0(0,0)$ & \\
\hline Moderate/severe & $9(56.2)$ & $7(43.8)$ & \\
\hline $\mathrm{T}$ & & & 0.74 \\
\hline 1 & $5(71.4)$ & $2(28.6)$ & \\
\hline 2 & $2(66.7)$ & $1(33.3)$ & \\
\hline 3 & $9(81.2)$ & $2(18.2)$ & \\
\hline $4 \mathrm{a}$ & $5(71.4)$ & $2(28.6)$ & \\
\hline $4 b$ & $1(100.0)$ & $0(0.0)$ & \\
\hline $\mathrm{N}$ & & & 0.45 \\
\hline N0 & $12(80.0)$ & $3(20.0)$ & \\
\hline $\mathrm{N} 1$ & $10(71.4)$ & $4(28.6)$ & \\
\hline M & & & 0.23 \\
\hline M0 & $20(80.0)$ & $5(20.0)$ & \\
\hline M1 & $2(50.0)$ & $2(50.0)$ & \\
\hline Stage & & & 0.022 \\
\hline I & $5(83.3)$ & $1(16.7)$ & \\
\hline II & - & - & \\
\hline III & $8(88.9)$ & $1(11.1)$ & \\
\hline IV & $9(64.3)$ & $5(35.7)$ & \\
\hline \multicolumn{4}{|l|}{ Treatment } \\
\hline Surgery & $11(84.6)$ & $2(15.4)$ & 0.75 \\
\hline Radiotherapy & $2(40.0)$ & $3(60.0)$ & \\
\hline Radiochemotherapy & $10(76.9)$ & $3(23.1)$ & \\
\hline
\end{tabular}

Statistical analysis was performed using the Fisher's exact test and Pearson's $\chi^{2}$ univariate analysis. Bold print indicates statistical significance.

correlation between weight loss and disease recurrence $(\mathrm{P}=0.007)$. It is known that patients with head and neck SCC are at high risk for weight loss due to the disease course and treatment, and that this weight loss ranges from 6 to $12 \%$ of the body weight (36-39). A prospective, randomized, multicenter trial demonstrated that a high body mass index (BMI $>25 \mathrm{~kg} / \mathrm{m}^{2}$ ) at the start of radiotherapy is positively associated with survival in patients with OPSCC (40). Furthermore, it has been demonstrated that severe weight loss is associated with worse quality of life (QoL), poorer treatment tolerance, delayed recovery, postoperative complications, prolonged hospitalization and an unfavorable prognosis (41-43). Additionally, weight loss was found to be strongly correlated with increased mortality rate (44). Loss of $\geq 5 \%$ of the body weight in 6 months is an unfavorable risk factor associated with decreased overall survival in HPV-related head and neck SCC patients (45). In a recent study, 2,399 patients with nasopharyngeal carcinoma were categorized as critical weight loss $(\mathrm{CWL} \geq 4.6 \%)$ or non-critical weight loss (non-CWL), and the results suggested that CWL is an independent prognostic factor for overall survival, treatment failure-free survival, and locoregional treatment failure-free survival, irrespective of chemotherapeutic modality, radiotherapy technique, or BMI (46).

The results presented in this study highlight that preventing therapy-associated weight loss should be a priority in these patients. Clinical guidelines recommend that enteral nutrition should be initiated if undernutrition is present or if food intake is markedly reduced for $>7-10$ days (47). However, further studies are required to determine the best enteral feeding methods (48) and the composition of the optimal supplemental formula (49). Furthermore, the effect of weight loss may be due to a complex interaction amongst multiple factors. Therefore, future studies should be focused on elucidating the association of these multiple factors with weight loss (50).

The main limitations of the present study are the retrospective nature of the analysis and the small sample size. 
Table III. Prognostic factors of mortality in patients with nasopharyngeal squamous cell carcinoma.

\begin{tabular}{|c|c|c|c|}
\hline Prognostic factors & Survivor group $\mathrm{n}=19(\%)$ & Deceased group $n=22(\%)$ & P-value \\
\hline Tumor subsite & & & 0.47 \\
\hline Tongue base & $10(45.5)$ & $12(54.5)$ & \\
\hline Tonsils & $4(30.8)$ & $9(69.2)$ & \\
\hline Soft palate & $5(83.3)$ & $1(16.7)$ & \\
\hline $\mathrm{T}$ & & & 0.003 \\
\hline 1 & $4(66.7)$ & $2(33.3)$ & \\
\hline 2 & $3(75.0)$ & $1(25.0)$ & \\
\hline 3 & $9(64.3)$ & $5(35.7)$ & \\
\hline $4 \mathrm{a}$ & $3(23.1)$ & $10(76.9)$ & \\
\hline $4 b$ & $0(0.0)$ & $4(100.0)$ & \\
\hline $\mathrm{N}$ & & & 0.01 \\
\hline N0 & $12(70.6)$ & $5(29.4)$ & \\
\hline $\mathrm{N} 1$ & $7(29.2)$ & $17(70.8)$ & \\
\hline M & & & $\mathbf{0 . 0 3 7}$ \\
\hline M0 & $18(54.5)$ & $15(45.5)$ & \\
\hline M1 & $1(12.5)$ & $7(87.5)$ & \\
\hline Stage & & & 0.0006 \\
\hline I & $4(80.0)$ & $1(20.0)$ & \\
\hline II & $1(100.0)$ & $0(0.0)$ & \\
\hline III & $8(80.0)$ & $2(20.0)$ & \\
\hline IV & $6(24.0)$ & $19(76.0)$ & \\
\hline Treatment & & & 0.018 \\
\hline Surgery & $9(75.0)$ & $3(25.0)$ & \\
\hline Radiotherapy & $1(33.3)$ & $2(66.7)$ & \\
\hline Radiochemotherapy & $9(37.5)$ & $15(62.5)$ & \\
\hline Palliative & $0(0.0)$ & $2(100.0)$ & \\
\hline Weight loss & & & 0.0001 \\
\hline None/mild & $13(86.7)$ & $2(13.3)$ & \\
\hline Moderate/severe & $6(23.1)$ & $20(76.9)$ & \\
\hline
\end{tabular}

The statistical analyses was performed using the Fisher's exact test and Pearson's $\chi^{2}$ univariate analysis. Bold print indicates statistical significance.

In conclusion, we herein demonstrated that moderate or severe weight loss at diagnosis is strongly associated with tumor recurrence. Regarding prognosis, OPSCC patients diagnosed at a more advanced TNM stage, patients treated with radiotherapy, chemoradiation or palliative treatment, and those patients with moderate or severe weight loss had a worse prognosis. It may be concluded that observation of the patient's weight may be important as an early indicator of tumor recurrence and an important prognostic factor of OPSCC.

\section{Acknowledgements}

The authors would like to thank the staff of the Hospital Universitário Santa Terezinha.

\section{Funding}

No funding was received.

\section{Availability of data and materials}

The datasets generated during and/or analyzed during the present study are available from the corresponding author on reasonable request.

\section{Authors' contributions}

ARB: Study concept and design; acquisition of data; analysis and interpretation of data; drafting of the manuscript; critical revision of the manuscript. KDH: Analysis and interpretation of data; drafting of the manuscript; critical revision of the manuscript. CB: Study concept and design; acquisition of data; analysis and interpretation of data; drafting of the manuscript; JSB: Study concept and design; acquisition of data; analysis and interpretation of data; drafting of the manuscript; RC: Study concept and design; acquisition of data; analysis and interpretation of data; drafting of the manuscript; SFB: Analysis and interpretation of data; drafting of the manuscript; critical revi- 
sion of the manuscript. CR: Analysis and interpretation of data drafting of the manuscript; critical revision of the manuscript. RAZ: Analysis and interpretation of data; drafting of the manuscript; critical revision of the manuscript. GB: Study concept and design; analysis and interpretation of data; drafting of the manuscript; critical revision of the manuscript.

\section{Ethics approval and consent to participate}

The present study was approved by the Institutional Ethics Committee (Comitê de Ética em Pesquisa Unoesc/HUST; approval no., 292.382).

\section{Patient consent for publication}

Not applicable.

\section{Competing interests}

The authors declare that they have no competing interests.

\section{References}

1. Weatherspoon DJ, Chattopadhyay A, Boroumand S and Garcia I: Oral cavity and oropharyngeal cancer incidence trends and disparities in the United States: 2000-2010. Cancer Epidemiol 39: 497-504, 2015.

2. Marur S and Forastiere AA: Head and neck cancer: Changing epidemiology, diagnosis, and treatment. Mayo Clin Proc 83: 489-501, 2008.

3. Pitchers M and Martin C: Delay in referral of oropharyngeal squamous cell carcinoma to secondary care correlates with a more advanced stage at presentation, and is associated with poorer survival. Br J Cancer 94: 955-958, 2006.

4. Howlader N, Noone AM, Krapcho M, Miller D, Bishop K, Kosary CL, Yu M, Ruhl J, Tatalovich Z, Mariotto A et al: SEER cancer statistics review, 1975-2014, national Cancer Institute. http://seer.cancer.gov/csr/1975_2014/. Accessed January, 17th, 2017.

5. Ferlay J, Soerjomataram I, Dikshit R, Eser S, Mathers C, Rebelo M, Parkin DM, Forman D and Bray F: Cancer incidence and mortality worldwide: Sources, methods and major patterns in GLOBOCAN 2012. Int J Cancer 136: E359-E386, 2015.

6. Haddad RI and Shin DM: Recent advances in head and neck cancer. N Engl J Med 359: 1143-1154, 2008.

7. Marklund L and Hammarstedt L: Impact of HPV in oropharyngeal cancer. J Oncol 2011: 509036, 2011.

8. Steinau M, Saraiya M, Goodman MT, Peters ES, Watson M, Cleveland JL, Lynch CF, Wilkinson EJ, Hernandez BY, Copeland G, et al: Human papillomavirus prevalence in oropharyngeal cancer before vaccine introduction, United States. Emerg Infect Dis 20: 822-828, 2014.

9. Sturgis EM and Cinciripini PM: Trends in head and neck cancer incidence in relation to smoking prevalence: An emerging epidemic of human papillomavirus-associated cancers? Cancer 110: 1429-1435, 2007.

10. Boing AF and Antunes JLF: Socioeconomic conditions and head and neck cancer: A systematic literature review. Cien Saude Colet 16: 615-622, 2011 (In Portuguese).

11. Warnakulasuriya S: Global epidemiology of oral and oropharyngeal cancer. Oral Oncol 45: 309-316, 2009.

12. Marron M, Boffetta P, Zhang ZF, Zaridze D, Wünsch-Filho V, Winn DM, Wei Q, Talamini R, Szeszenia-Dabrowska N, Sturgis EM, et al: Cessation of alcohol drinking, tobacco smoking and the reversal of head and neck cancer risk. Int J Epidemiol 39: 182-196, 2010.

13. McIlwain WR, Sood AJ, Nguyen SA and Day TA: Initial symptoms in patients with HPV-positive and HPV-negative oropharyngeal cancer. JAMA Otolaryngol Head Neck Surg 140 441-447, 2014.

14. Ward MJ, Mellows T, Harris S, Webb A, Patel NN, Cox HJ, Piper K, Ottensmeier CH, Thomas GJ and King EV: Staging and treatment of oropharyngeal cancer in the human papillomavirus era. Head Neck 37: 1002-1013, 2015.
15. Ang KK, Harris J, Wheeler R, Weber R, Rosenthal DI, Nguyen-Tân PF, Westra WH, Chung CH, Jordan RC, Lu C, et al: Human papillomavirus and survival of patients with oropharyngeal cancer. N Engl J Med 363: 24-35, 2010.

16. Suzuki T, Wakai K, Matsuo K, Hirose K, Ito H, Kuriki K, Sato S, Ueda R, Hasegawa Y and Tajima K: Effect of dietary antioxidants and risk of oral, pharyngeal and laryngeal squamous cell carcinoma according to smoking and drinking habits. Cancer Sci 97: 760-767, 2006.

17. Garavello W, Lucenteforte E, Bosetti C, Talamini R, Levi F, Tavani A, Franceschi S, Negri E and La Vecchia C: Diet diversity and the risk of laryngeal cancer: A case-control study from Italy and Switzerland. Oral Oncol 45: 85-89, 2009.

18. Franco EL, Kowalski LP, Oliveira BV, Curado MP, Pereira RN, Silva ME, Fava AS and Torloni H: Risk factors for oral cancer in Brazil: A case-control study. Int J Cancer 43: 992-1000, 1989.

19. Fonseca CA, Otto SS, Paumgartten FJ and Leitão AC: Nontoxic, mutagenic, and clastogenic activities of Mate-Chimarrão (Ilex paraguariensis). J Environ Pathol Toxicol Oncol 19: 333-346, 2000.

20. Deneo-Pellegrini H, De Stefani E, Boffetta P, Ronco AL, Acosta G, Correa P and Mendilaharsu M: Maté consumption and risk of oral cancer: Case-control study in Uruguay. Head Neck 35: 1091-1095, 2013.

21. Würdemann N, Wagner S, SharmaSJ,PriggeES, Reuschenbach M, Gattenlöhner S, Klussmann JP and Wittekindt C: Prognostic impact of AJCC/UICC 8th edition new staging rules in oropharyngeal squamous cell carcinoma. Front Oncol 7: 129, 2017.

22. Baicus C, Rimbas M, Baicus A and Caraiola S; Grupul de Studiu al Scaderii Ponderale Involuntare: Cancer and involuntary weight loss: Failure to validate a prediction score. PLoS One 9: e95286, 2014

23. Jager-Wittenaar H, Dijkstra PU, Vissink A, van der Laan BF, van Oort RP and Roodenburg JL: Critical weight loss in head and neck cancer-prevalence and risk factors at diagnosis: An explorative study. Support Care Cancer 15: 1045-1050, 2007.

24. Deschler DG, Moore MG and Smith RV: (eds). Quick reference guide to TNM staging of head and neck cancer and neck dissection classification, 4th edition. Alexandria, VA, American Academy of Otolaryngology-Head and Neck Surgery Foundation, 2014.

25. Blackburn GL, Bistrian BR, Maini BS, Schlamm HT and Smith MF: Nutritional and metabolic assessment of the hospitalized patient. JPEN J Parenter Enteral Nutr 1: 11-22, 1977.

26. Lybak S, Liavaag PG, Monge OR and Olofsson J: Surgery and postoperative radiotherapy a valid treatment for advanced oropharyngeal carcinoma. Eur Arch Otorhinolaryngol 268: 449-456, 2011

27. Zumsteg ZS, Cook-Wiens G, Yoshida E, Shiao SL, Lee NY, Mita A, Jeon C, Goodman MT and Ho AS: Incidence of oropharyngeal cancer among elderly patients in the United States. JAMA Oncol 2: 1617-1623, 2016.

28. Perry BJ, Zammit AP, Lewandowski AW, Bashford JJ, Dragovic AS, Perry EJ, Hayatbakhsh R and Perry CF: Sites of origin of oral cavity cancer in nonsmokers vs smokers: Possible evidence of dental trauma carcinogenesis and its importance compared with human papillomavirus. JAMA Otolaryngol Head Neck Surg 141: 5-11, 2015.

29. Garden AS, Dong L, Morrison WH, Stugis EM, Glisson BS Frank SJ, Beadle BM, Gunn GB, Schwartz DL, Kies MS, et al: Patterns of disease recurrence following treatment of oropharyngeal cancer with intensity modulated radiation therapy. Int $\mathrm{J}$ Radiat Oncol Biol Phys 85: 941-947, 2013.

30. Roskies M,Kay-Rivest E, Mascarella MA, Sultanem K, Mlynarek A and Hier M: Survival outcomes in patients with oropharyngeal cancer treated with carboplatin/paclitaxel and concurrent radiotherapy. J Otolaryngol Head Neck Surg 45: 50, 2016.

31. Snow GB, Annyas AA, van Slooten EA, Bartelink H and Hart AA: Prognostic factors of neck node metastasis. Clin Otolaryngol Allied Sci 7: 185-192, 1982.

32. Wenzel S, Sagowski C, Kehrl W and Metternich FU: The prognostic impact of metastatic pattern of lymph nodes in patients with oral and oropharyngeal squamous cell carcinomas. Eur Arch Otorhinolaryngol 261: 270-275, 2004.

33. Huang SH, Xu W, Waldron J, Siu L, Shen X, Tong L, Ringash J, Bayley A, Kim J, Hope A, et al: Refining American joint committee on cancer/union for international cancer control TNM stage and prognostic groups for human papillomavirus-related oropharyngeal carcinomas. J Clin Oncol 33: 836-845, 2015.

34. Mashberg A and Meyers H: Anatomical site and size of 222 early asymptomatic oral squamous cell carcinomas: A continuing prospective study of oral cancer. II. Cancer 37: 2149-2157, 1976. 
35. Abdo EN, Garrocho Ade A, Barbosa AA, Oliveira EL, Franca-Filho L, Negri SL and Pordeus IA: Time elapsed between the first symptoms, diagnosis and treatment of oral cancer patients in Belo Horizonte, Brazil. Med Oral Patol Oral Cir Bucal 12: E469-E473, 2007.

36. Munshi A, Pandey MB, Durga T, Pandey KC, Bahadur S and Mohanti BK: Weight loss during radiotherapy for head and neck malignancies: What factors impact it? Nutr Cancer 47: 136-140, 2003.

37. Pressoir M, Desné S, Berchery D, Rossignol G, Poiree B, Meslier M, Traversier S, Vittot M, Simon M, Gekiere JP, et al: Prevalence, risk factors and clinical implications of malnutrition in French Comprehensive Cancer Centres. Br J Cancer 102: 966-971, 2010

38. Trotti A, Bellm LA, Epstein JB, Frame D, Fuchs HJ, Gwede CK, Komaroff E, Nalysnyk L and Zilberberg MD: Mucositis incidence, severity and associated outcomes in patients with head and neck cancer receiving radiotherapy with or without chemotherapy: A systematic literature review. Radiother Oncol 66: 253-262, 2003

39. Chasen MR and Bhargava R: A descriptive review of the factors contributing to nutritional compromise in patients with head and neck cancer. Support Care Cancer 17: 1345-1351, 2009.

40. Ottosson S, Söderström K, Kjellén E, Nilsson P, Zackrisson B and Laurell G: Weight and body mass index in relation to irradiated volume and to overall survival in patients with oropharyngeal cancer: A retrospective cohort study. Radiat Oncol 9: 160, 2014.

41. Nourissat A, Vasson MP, Merrouche Y, Bouteloup C, Goutte M, Mille D, Jacquin JP, Collard O, Michaud P and Chauvin F: Relationship between nutritional status and quality of life in patients with cancer. Eur J Cancer 44: 1238-1242, 2008.

42. Ravasco P, Monteiro-Grillo I, Marques Vidal P and Camilo ME: Impact of nutrition on outcome: A prospective randomized controlled trial in patients with head and neck cancer undergoing radiotherapy. Head Neck 27: 659-668, 2005.

43. Gourin CG, Couch ME and Johnson JT: Effect of weight loss on short-term outcomes and costs of care after head and neck cancer surgery. Ann Otol Rhinol Laryngol 123: 101-110, 2014.
44. Nguyen TV and Yueh B: Weight loss predicts mortality after recurrent oral cavity and oropharyngeal carcinomas. Cancer 95: 553-562, 2002

45. Argiris A, Li S, Ghebremichael M, Egloff AM, Wang L, Forastiere AA, Burtness B and Mehra R: Prognostic significance of human papillomavirus in recurrent or metastatic head and neck cancer: An analysis of Eastern Cooperative Oncology Group trials. Ann Oncol 25: 1410-1416, 2014.

46. Zeng Q, Shen LJ, Guo X, Guo XM, Qian CN and Wu PH: Critical weight loss predicts poor prognosis in nasopharyngeal carcinoma. BMC Cancer 16: 169, 2016.

47. Arends J, Bodoky G, Bozzetti F, Fearon K, Muscaritoli M, Selga G, van Bokhorst-de van der Schueren MA, von Meyenfeldt M; DGEM (German Society for Nutritional Medicine), Zürcher G, Fietkau R, Aulbert E, Frick B, Holm M, Kneba M, Mestrom HJ, Zander A; ESPEN (European Society for Parenteral and Enteral Nutrition): ESPEN guidelines on enteral nutrition: Non-surgical oncology. Clin Nutr 25: 245-259, 2006.

48. Rabinovitch R, Grant B, Berkey BA, Raben D, Ang KK, Fu KK and Cooper JS; Radiation Therapy Oncology Group: Impact of nutrition support on treatment outcome in patients with locally advanced head and neck squamous cell cancer treated with definitive radiotherapy: A secondary analysis of RTOG trial 90-03. Head Neck 28: 287-296, 2006.

49. Corry J, Poon W, McPhee N, Milner AD, Cruickshank D, Porceddu SV, Rischin D and Peters LJ: Prospective study of percutaneous endoscopic gastrostomy tubes versus nasogastric tubes for enteral feeding in patients with head and neck cancer undergoing (chemo)radiation. Head Neck 31: 867-876, 2009.

50. Zhao JZ, Zheng H, Li LY, Zhang LY, Zhao Y and Jiang N: Predictors for weight loss in head and neck cancer patients undergoing radiotherapy: A systematic review. Cancer Nurs 38: E37-E45, 2015 